\title{
FRUIT AND VEGETABLE JUICE FERMENTATION WITH BIFIDOBACTERIA
}

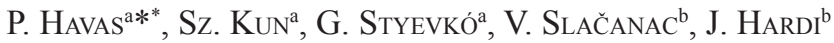 \\ and J. REZESSY-SZABÓ ${ }^{\mathrm{a}}$ \\ ${ }^{a}$ Brewing and Distilling Department, Faculty of Food Science, Corvinus University of Budapest, \\ H-1118 Budapest, Ménesi út 45. Hungary \\ ${ }^{b}$ Faculty of Food Technology, J.J. Strossmayer University, Franje Kuhača 18, 31000 Osijek. Croatia
}

(Received: 13 April 2014; accepted: 14 July 2014)

\begin{abstract}
Consumers are becoming more interested in healthy nutrition. To meet consumer requirements, the possibility of the fruit and vegetable juice fermentation by bifidobacteria was investigated. Sour cherry, orange, carrot, and tomato juice was fermented with five Bifidobacterium strains (from human origin and starter culture). The tested strains have grown well in orange, carrot, and tomato juices. The B. longum Bb-46 strain demonstrated the best growth activities. It was found that ratio of the produced acetic and lactic acids are dependent on the Bifidobacterium strain rather than on the fermentation medium. The most intensive inhibition was observed against the Campylobacter jejuni strain. In course of the fermentation the antioxidant capacities slightly decreased, except when the orange juice was fermented with $B$. lactis Bb-12 and B. longum A4.8. The obtained results may contribute to the design of a novel functional food product.

Keywords: Bifidobacterium, vegetable, fruit, antimicrobial effect
\end{abstract}

Activity of microorganisms is utilized to produce food and beverages for thousands of years. Food produced with spontaneous fermentation forms as a result of the activity of a complex microbiota. Due to the development of food and nutrition science, the potential probiotic strains have got great importance in the selection of industrial microorganisms, to be used in food processing. The most widely used probiotics are found among lactic acid bacteria (mostly lactobacilli and bifidobacteria) (SCARDOvi, 1981). The probiotic foods are a large segment of functional food products. Most probiotic preparations on the market are dairy products (based on milk and its derivates). The demand of consumers for non-dairy based probiotic products, like fermented soy-based products, vegetable and fruit juices, is increasing in recent years. Vegetables, fruit, and their juices have several beneficial effects for human health, because they are rich in antioxidants, vitamins, fibres, and minerals, and are consumed by a large percentage of the global population. Vegetable and fruit juices may also serve as media for cultivating probiotics. The bioactive components may be absorbed even better from juices than from plant tissues (BRAndt et al., 2004; Luckow \& DelahunTy, 2004). The carrot is an excellent source of potassium and $\beta$-carotene, which is regarded as a provitamin for vitamin $\mathrm{A}$; it contains vitamin $\mathrm{C}$, vitamin $\mathrm{B}_{6}$, thiamine, folic acid, and magnesium. Among the carotenoids, the $\beta$-carotene $(2-10 \mathrm{mg} / 100 \mathrm{~g})$ is the most important, and it gives carrots their distinctive orange colour (HERRMANN, 2001). The tomato is the richest source of

* To whom correspondence should be addressed.

Phone:+36-1-482-6027; fax: +36-1-482-6558; e-mail: havas.bt@gmail.com

0239-3006/\$20.00 @ 2014 Akadémiai Kiadó, Budapest 
lycopene in the diet. Lycopene can act as antioxidant, enhance cell-to-cell communication, and modulate cell-cycle progression. Tomato also contains folate, vitamins $\mathrm{C}$, A, and E, potassium, various other carotenoids, and phytochemicals, such as polyphenols (quercetin, naringenin). Orange is a very good source of vitamins, especially vitamin C. Oranges also contain a sufficient amount vitamin $\mathrm{A}$, other flavonoid antioxidants $(\alpha$ and $\beta$-carotenes, $\beta$-cryptoxanthin, zeaxanthin, and lutein), B-complex vitamins (thiamin, pyridoxine, folates), potassium, and calcium. The sour cherry is rich in anthocyanins, vitamins $\mathrm{C}, \mathrm{A}, \mathrm{B}$, and in calcium, potassium, magnesium, iron, and zinc. The anthocyanins and cyanidin isolated from sour cherries had antioxidant and anti-inflammatory properties (PENNINGTON, 2002; Eskin \& TAMIR, 2006).

Protective and nutritive properties of these juices or drinks are improved through fermentation with probiotic bacteria (SAARela et al., 2011). Probiotic lactic acid bacteria, Lactobacillus, Streptococcus, and Bifidobacterium species have health-promoting properties by maintaining an improved intestinal bacterial composition, stimulating the immune response, having antimutagenic effect, protecting against infection, etc. (KAUR et al., 2002; MerCenier et al., 2002). Among starter cultures, Bifidobacterium lactis Bb-12 (Chr. Hansen) is widely used in the dairy industry, because this strain has numerous physiological and technological advantages. In human studies, B. lactis Bb-12 has shown efficacy in prevention of traveller's diarrhoea, treatment of rotavirus diarrhoea, modulation of intestinal microbiota, and alleviation of atopic dermatitis symptoms in children (AlANDER et al., 2001).

The goal of this study was to assess suitability of raw material from plant origin as a substrate for growth of selected probiotic bacteria, and to make trials for preparation of nondairy products with these strains, because raw materials do not contain dairy allergens that might prevent usage by certain segment of the population (NETZEL et al., 2002; LAVERMICOCCA, 2006).

\section{Materials and methods}

\subsection{Micro-organisms and their maintenance}

The following Bifidobacterium and test strains were used in this study: Bifidobacterium lactis Bb-12 (Chr. Hansen, Denmark), B. bifidum B3.2 (human isolate, MAYER et al., 2003), B. longum A4.8 (human isolate, MAYER et al., 2003), B. longum Bb-46 (Chr. Hansen), B. bifidum NCFB (National Collection of Food Bacteria) 1454, and Staphylococcus aureus, Salmonella enteritidis, Campylobacter jejuni, Candida albicans (Institute of Public Health in Osijek: Collection of digestive and urinary pathogens).

Bifidobacteria were grown anaerobically (in Bugbox anaerobic chamber, Ruskin Technology) at $37^{\circ} \mathrm{C}$ for $48 \mathrm{~h}$ in TPY (Trypticase-Phytone-Yeast) medium (MAYER et al., 2003). Test strains were grown on Mueller-Hinton plates, incubated at $37{ }^{\circ} \mathrm{C}$ for $24 \mathrm{~h}$ before analysis (SlaČAnAC et al., 2004).

Media and raw materials: Fermentation experiments were carried out in fruit (Happy Day Orange and Sour cherry by Rauch) and vegetable (Happy Day Tomato by Rauch and Naturpur Carrot by Spar) juices. The juices contained no preservatives and were purchased in retail store. The initial $\mathrm{pH}$ was set to $6.10-6.20$. 


\subsection{Applied methods}

1.2.1. Conditions of fermentation. Fermentation was initiated with defined concentration of the relevant Bifidobacterium strains. All trials were carried out under anaerobic conditions in Anaerobe Jar+GasPak System (OXOID) or in Bugbox anaerobic chamber at $37{ }^{\circ} \mathrm{C}$. Fermentation was followed by counting the colony forming units (CFU) and measuring the $\mathrm{pH}$. In some cases the spectrum of organic acids and the quantities of typical acids were also determined.

1.2.2. Determination of colony forming units. Beeren's agar was used to determine the concentration of Bifidobacteria (BEEREN's, 1990). Serial tenfold dilutions were prepared from the ferment broth. The diluted samples were transferred into Petri dishes and mixed with the appropriate medium. The plates were incubated under anaerobic conditions in Anaerobe Jar+GasPak System or in Bugbox anaerobic chamber at $37^{\circ} \mathrm{C}$. The colonies were counted after 48 or $72 \mathrm{~h}$ incubation.

1.2.3. Determination of antagonistic activity. The measurements were done according to TAGG and McGiven (1971).

1.2.4. Determination of organic acids by HPLC. The samples were centrifuged at 14000 r.p.m. for $10 \mathrm{~min}$ and the supernatants were filtered through $0.45 \mu \mathrm{m}$ polyvinylidene difluoride membrane (Waters, Milford, MA, USA) before injection. Acetic and lactic acid contents were measured with HPLC equipment with the following technical data: Detector: PDA detector (210 nm); column: Aminex HPX-87H; mobile phase: $5 \mathrm{mM} \mathrm{H}_{2} \mathrm{SO}_{4}$; flow rate: $0.5 \mathrm{ml}$ $\min ^{-1}$; column and detector temperature: $45^{\circ} \mathrm{C}$.

1.2.5. Determination of antioxidant capacity. The Blois's method was applied, which is based on the binding of DPPH radicals (BLOIS, 1958).

\section{Results and discussion}

\subsection{Ability of growth in fruit and vegetable juice}

Tested Bifidobacterium strains utilized sour cherry and orange juice well, but to varying degree. By the $24^{\text {th }}$ hour of fermentation, the cell concentration increased two orders of magnitude, in some cases three orders of magnitude. The best growth ability was achieved by B. longum Bb-46 in orange juice, reaching $0.344 \mathrm{~h}^{-1}$ growth rate. Cell count increased three orders of magnitude: from the initial $6.2 \times 10^{6} \mathrm{CFU} \mathrm{m}^{-1}$ to $1.8 \times 10^{9} \mathrm{CFU} \mathrm{ml}^{-1}$ by the end of the fermentation. The weakest growth activity was shown by the B. bifidum NCFB 1454 strain both in sour cherry and orange juice, which is well reflected in the growth rate values $(0.108$ $\mathrm{h}^{-1}$ and $0.14 \mathrm{~h}^{-1}$ ). Comparing the changes of cell concentration in sour cherry and orange juice, it can be stated that the strains had shown better growth and metabolic activity in orange juice. It was demonstrated through the growth rate and generation time (Tables 1 and 2). Furthermore, the $\mathrm{pH}$ values confirmed, that initial $\mathrm{pH}$ values $(\mathrm{pH}=6.2)$ of the orange juice decreased to $\mathrm{pH}=4.15-4.73$ after the $24^{\text {th }} \mathrm{h}$ of fermentation. In the sour cherry fermentation the $\mathrm{pH}$ value was reduced approximately to 5.0. 
Table 1. Change of cell concentration, $\mathrm{pH}$, growth rate, and generation time of Bifidobacterium strains in fermented sour cherry juice

\begin{tabular}{|c|c|c|c|c|c|c|}
\hline \multirow[t]{2}{*}{$\begin{array}{l}\text { Bifidobacterium } \\
\text { strains }\end{array}$} & \multicolumn{2}{|c|}{$\begin{array}{l}\text { Cell concentration } \\
\left(\log \left[\mathrm{CFU} \mathrm{m}{ }^{-1}\right]\right)\end{array}$} & \multicolumn{2}{|c|}{$\mathrm{pH}$} & \multirow[t]{2}{*}{$\mu_{\max }\left(h^{-1}\right)$} & \multirow[t]{2}{*}{$t_{g}(h)$} \\
\hline & Initial & Final & Initial & Final & & \\
\hline A 4.8 & $6.13 \pm 0.11$ & $8.04 \pm 0.20$ & 6.20 & 5.10 & 0.222 & 3.12 \\
\hline Bb-12 & $6.91 \pm 0.18$ & $8.71 \pm 0.14$ & 6.20 & 4.52 & 0.198 & 3.50 \\
\hline $\mathrm{Bb}-46$ & $6.42 \pm 0.13$ & $8.49 \pm 0.43$ & 6.20 & 4.66 & 0.257 & 2.69 \\
\hline B3.2 & $6.92 \pm 0.21$ & $8.59 \pm 0.29$ & 6.20 & 5.14 & 0.167 & 4.15 \\
\hline NCFB1454 & $6.51 \pm 0.16$ & $7.50 \pm 0.16$ & 6.20 & 5.34 & 0.108 & 6.40 \\
\hline
\end{tabular}

Values are averages of triplicate results \pm standard deviation

Table 2. Change of cell concentration, $\mathrm{pH}$, growth rate, and generation time of Bifidobacterium strains in fermented orange juice

\begin{tabular}{|c|c|c|c|c|c|c|}
\hline \multirow[t]{2}{*}{$\begin{array}{l}\text { Bifidobacterium } \\
\text { strains }\end{array}$} & \multicolumn{2}{|c|}{$\begin{array}{l}\text { Cell concentration } \\
\left(\log \left[\mathrm{CFU} \mathrm{ml} l^{-1}\right]\right)\end{array}$} & \multicolumn{2}{|c|}{$\mathrm{pH}$} & \multirow[t]{2}{*}{$\mu_{\max }\left(h^{-1}\right)$} & \multirow[t]{2}{*}{$\mathrm{t}_{\mathrm{g}}(\mathrm{h})$} \\
\hline & Initial & Final & Initial & Final & & \\
\hline A 4.8 & $6.30 \pm 0.15$ & $8.41 \pm 0.31$ & 6.20 & 4.73 & 0.266 & 2.60 \\
\hline Bb-12 & $7.14 \pm 0.21$ & $8.73 \pm 0.15$ & 6.20 & 4.15 & 0.151 & 4.59 \\
\hline $\mathrm{Bb}-46$ & $6.79 \pm 0.19$ & $9.25 \pm 0.39$ & 6.20 & 4.25 & 0.344 & 2.01 \\
\hline B3.2 & $7.20 \pm 0.44$ & $9.51 \pm 0.17$ & 6.20 & 4.28 & 0.309 & 2.24 \\
\hline NCFB1454 & $6.97 \pm 0.11$ & $8.51 \pm 0.52$ & 6.20 & 4.63 & 0.140 & 4.94 \\
\hline
\end{tabular}

Values are averages of triplicate results \pm standard deviation

To compare the growth of applied strains in different natural media, fermentations in vegetable juices were also performed. Results showed that vegetable juices provided better growth media for the tested strains. The best growth was shown by the B. lactis Bb-12, $B$. longum $\mathrm{Bb}-46$, and $B$. longum A4.8 strains in carrot juice. The highest cell concentrations $\left(8.12 \times 10^{8}\right.$ and $\left.1.25 \times 10^{9} \mathrm{CFU} \mathrm{ml}^{-1}\right)$ were detected in the 12 to $20 \mathrm{~h}$ range, and the growth rates were between $0.264 \mathrm{~h}^{-1}$ and $0.339 \mathrm{~h}^{-1}$ (Table 3). In tomato juice, the highest growth rate and viable cell number at the end of fermentation were found in samples fermented with $B$. longum Bb-46, B. bifidum B3.2, and B. longum A4.8 strains. The cell concentration of B. longum Bb46 and B. bifidum B3.2 increased by about $3 \log \mathrm{CFU} \mathrm{ml}^{-1}$ and the specific growth rate was $0.323 \mathrm{~h}^{-1}$ and $0.275 \mathrm{~h}^{-1}$ (Table 4.). Kamaly (1997) reported similar results in the case of $B$. longum and B. bifidum when it was grown in soy milk. The intensive metabolic activity was demonstrated by the evolution of $\mathrm{pH}$ values. The $\mathrm{pH}$ values were $\mathrm{pH}=4.31-4.92$ in the $24^{\text {th }}$ of fermentation both in carrot and in tomato juices. 
Table 3. Change of cell concentration, $\mathrm{pH}$, growth rate, and generation time of Bifidobacterium strains in fermented carrot juice

\begin{tabular}{|c|c|c|c|c|c|c|}
\hline \multirow[t]{2}{*}{$\begin{array}{l}\text { Bifidobacterium } \\
\text { strains }\end{array}$} & \multicolumn{2}{|c|}{$\begin{array}{l}\text { Cell concentration } \\
\left(\log \left[\mathrm{CFU} \mathrm{m}{ }^{-1}\right]\right)\end{array}$} & \multicolumn{2}{|c|}{$\mathrm{pH}$} & \multirow[t]{2}{*}{$\mu_{\max }\left(h^{-1}\right)$} & \multirow[t]{2}{*}{$\mathrm{t}_{\mathrm{g}}(\mathrm{h})$} \\
\hline & Initial & Final & Initial & Final & & \\
\hline A 4.8 & $6.43 \pm 0.20$ & $8.94 \pm 0.27$ & 6.10 & 4.39 & 0.339 & 2.04 \\
\hline $\mathrm{Bb}-12$ & $6.43 \pm 0.09$ & $8.64 \pm 0.16$ & 6.10 & 4.64 & 0.264 & 2.63 \\
\hline $\mathrm{Bb}-46$ & $6.55 \pm 0.16$ & $8.82 \pm 0.47$ & 6.10 & 4.64 & 0.264 & 2.63 \\
\hline B3.2 & $6.41 \pm 0.10$ & $8.74 \pm 0.36$ & 6.10 & 4.92 & 0.202 & 3.43 \\
\hline NCFB1454 & $6.69 \pm 0.12$ & $8.17 \pm 0.34$ & 6.10 & 4.64 & 0.200 & 3.47 \\
\hline
\end{tabular}

Values are averages of triplicate results \pm standard deviation.

Table 4. Change of cell concentration, $\mathrm{pH}$, growth rate, and generation time of Bifidobacterium strains in fermented tomato juice

\begin{tabular}{|c|c|c|c|c|c|c|}
\hline \multirow[t]{2}{*}{$\begin{array}{l}\text { Bifidobacterium } \\
\text { strains }\end{array}$} & \multicolumn{2}{|c|}{$\begin{array}{l}\text { Cell concentration } \\
\left(\log \left[\mathrm{CFU} \mathrm{m}{ }^{-1}\right]\right)\end{array}$} & \multicolumn{2}{|c|}{$\mathrm{pH}$} & \multirow[t]{2}{*}{$\mu_{\max }\left(h^{-1}\right)$} & \multirow[t]{2}{*}{$\mathrm{t}_{\mathrm{g}}(\mathrm{h})$} \\
\hline & Initial & Final & Initial & Final & & \\
\hline A 4.8 & $6.96 \pm 0.11$ & $8.71 \pm 0.27$ & 6.10 & 4.60 & 0.371 & 1.87 \\
\hline $\mathrm{Bb}-12$ & $6.35 \pm 0.10$ & $8.56 \pm 0.15$ & 6.10 & 4.39 & 0.151 & 4.59 \\
\hline $\mathrm{Bb}-46$ & $6.94 \pm 0.29$ & $9.17 \pm 0.48$ & 6.10 & 4.31 & 0.323 & 2.15 \\
\hline B3.2 & $6.83 \pm 0.26$ & $9.11 \pm 0.18$ & 6.10 & 4.40 & 0.275 & 2.52 \\
\hline NCFB1454 & $6.55 \pm 0.37$ & $7.81 \pm 0.46$ & 6.10 & 4.56 & 0.234 & 2.96 \\
\hline
\end{tabular}

Values are averages of triplicate results \pm standard deviation.

\subsection{Change of acetic and lactic acid contents}

It is well known that bifidobacteria produce mainly acetate and lactate from carbohydrate catabolism by the bifidus pathway, yielding $2 \mathrm{~mol}$ of lactic acid and $3 \mathrm{~mol}$ of acetic acid per 2 mol of glucose in synthetic medium (BIAVATI et al., 2000). The production of these acids was determined to evaluate the metabolic activity of the applied strains. Table 5 shows the acetic acid to lactic acid ratio. $B$. lactis $\mathrm{Bb}-12$ showed the lowest acetic to lactic acid ratios (0.05-0.88), while B. bifidum NCFB 1454 the highest ones (9.6-12.28). Based on these data it was found that ratio of the two acids are dependent on the Bifidobacterium strain rather than on the fermentation medium. SCALABRINI and co-workers (1998) observed the same phenomenon when they fermented soy milk with 13 different $B$. longum and 4 different $B$. bifidum strains. According to several reports, it is desirable that fermented products contain low quantities of acetic acid, because of its disagreeable taste. The favourable acetic to lactic acid ratio that was produced by $\mathrm{B}$. lactis $\mathrm{Bb}-12$ in all juices of plant origin gives one more evidence of being one of the best industrial strains. 
Table 5. Acetic acid to lactic acid ratio at the end of fermentation

\begin{tabular}{lcccc}
\hline \multirow{2}{*}{ Bifidobacterium strains } & \multicolumn{4}{c}{ Acetic acid/Lactic acid rate } \\
\cline { 2 - 5 } & Orange & Sour cherry & Carrot & Tomato \\
\hline A4.8 & 2.99 & 1.03 & 1.83 & 1.33 \\
Bb-12 & 0.18 & 0.88 & 0.23 & 0.05 \\
Bb-46 & 3.52 & 1.97 & 0.41 & 0.15 \\
B3.2 & 1.81 & 1.36 & 2.77 & 0.13 \\
NCFB1454 & 9.60 & 2.87 & 2.38 & 12.28 \\
\hline
\end{tabular}

\subsection{Inhibition effect of fermented vegetable and fruit juices}

The antimicrobial effects of fruit and vegetable juices fermented by Bifidobacterium against entero- and uropathogenic microorganisms (Staphylococcus aureus, Salmonella enteritidis, Campylobacter jejuni, Candida albicans) were determined. They are sources of danger from the clinical aspect to the human body. Table 6 shows the antagonistic activity of control (unfermented) fruit and vegetable juices, juice with adjusted $\mathrm{pH}$ (6.2), and juices fermented with Bifidobacterium strains.

The most intensive inhibition was observed against the Campylobacter jejuni strain (Fig. 1). Probably due to acidity, natural orange juice exerted a strong inhibition effect, which was not reduced even after the fermentation with B. bifidum B3.2 strain. In case of the original sour cherry juice and the one fermented with B. longum A4.8 strain, a wide range of inhibition was observed, but in other cases the inhibition effect was reduced. The antagonistic effect of carrot juices fermented by B. lactis Bb-12 and B. longum A4.8 was increased compared to the control sample. These are certainly reassuring results. Another good result is that the tomato juices fermented by bifidobacteria showed increased inhibiting effect except in case of $B$. bifidum B3.2. Antagonistic activity of fermented orange-, carrot-, and tomato juices against Salmonella enteritidis was remarkable, whereas the raw material did not show such activity against the test strains. The improved inhibition effect was due to the metabolism of Bifidobacterium strains. The strongest inhibition against the Salmonella strain was obtained
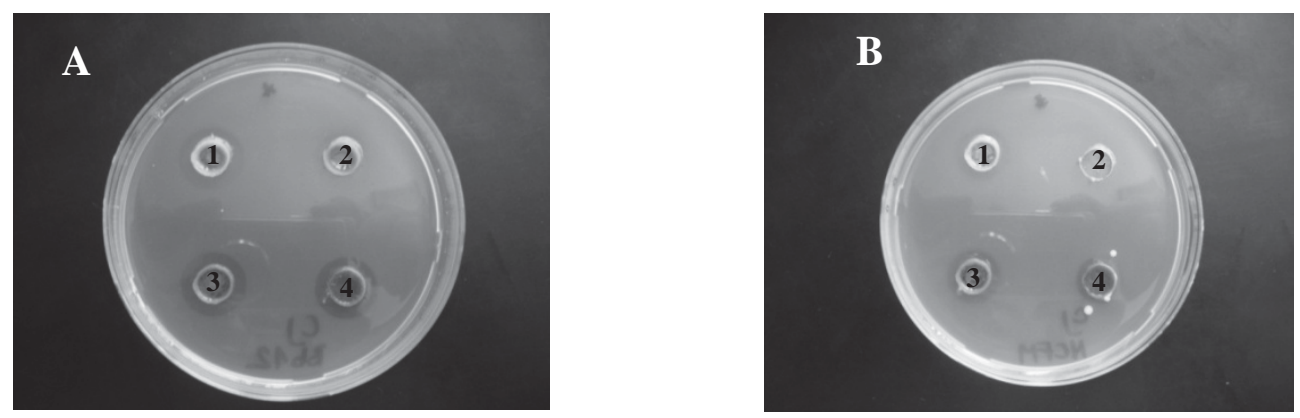

Fig. 1. Inhibition effect against Campylobacter jejuni strain of fermented orange (1), sour cherry (2), carrot (3), and tomato (4) juice by B. lactis Bb-12 (A) and B. bifidum NCFB 1454 (B) strains 
using B. lactis Bb-12, B. bifidum B3.2, and B. longum Bb-46 for the fermentation. In case of Staphylococcus aureus test strain, only partial inhibition was detected. Against the Staphylococcus strain, clear inhibition was observed only in case of orange juice fermented by $\mathrm{B}$. lactis $\mathrm{Bb}-12$ and carrot juice fermented by $\mathrm{B}$. longum $\mathrm{Bb}-46$. Candida albicans was resistant against the samples. Table 6 summarizes the sensitivity that was shown by different test strains against the Bifidobacterium strains.

Table 6. Inhibition effect against test strains in control, adjusted $\mathrm{pH}$ (6.2), and fermented juices

\begin{tabular}{|c|c|c|c|c|c|}
\hline & Sample & $\begin{array}{l}\text { Staphylococ- } \\
\text { cus aureus }\end{array}$ & $\begin{array}{c}\text { Salmonella } \\
\text { enteritidis }\end{array}$ & $\begin{array}{c}\text { Campylobac- } \\
\text { ter jejuni }\end{array}$ & $\begin{array}{l}\text { Candida } \\
\text { albicans }\end{array}$ \\
\hline \multirow[t]{7}{*}{ Orange juice } & Raw material & \pm & - & +++ & - \\
\hline & Adjusted pH & \pm & - & +++ & - \\
\hline & Bb-12 & ++ & ++ & +++ & - \\
\hline & B3.2 & - & + & - & - \\
\hline & NCFB 1454 & \pm & \pm & +++ & - \\
\hline & Bb-46 & + & ++ & +++ & - \\
\hline & A 4.8 & \pm & - & +++ & - \\
\hline \multirow{7}{*}{$\begin{array}{l}\text { Sour cherry } \\
\text { juice }\end{array}$} & Raw material & ++ & \pm & +++ & - \\
\hline & Adjusted $\mathrm{pH}$ & \pm & \pm & \pm & - \\
\hline & Bb-12 & \pm & + & ++ & - \\
\hline & B3.2 & \pm & \pm & \pm & - \\
\hline & NCFB 1454 & \pm & - & \pm & - \\
\hline & $\mathrm{Bb}-46$ & \pm & ++ & \pm & - \\
\hline & A 4.8 & \pm & - & ++ & - \\
\hline \multirow[t]{7}{*}{ Carrot juice } & Raw material & - & - & ++ & - \\
\hline & Adjusted $\mathrm{pH}$ & \pm & - & - & - \\
\hline & $\mathrm{Bb}-12$ & ++ & ++ & +++ & - \\
\hline & B3.2 & + & ++ & + & - \\
\hline & NCFB 1454 & \pm & \pm & ++ & - \\
\hline & $\mathrm{Bb}-46$ & ++ & ++ & ++ & - \\
\hline & A4. 8 & \pm & \pm & +++ & - \\
\hline \multirow[t]{7}{*}{ Tomato juice } & Raw material & \pm & - & + & - \\
\hline & Adjusted pH & \pm & - & - & - \\
\hline & $\mathrm{Bb}-12$ & + & ++ & +++ & - \\
\hline & B3.2 & \pm & ++ & \pm & - \\
\hline & NCFB 1454 & \pm & \pm & ++ & - \\
\hline & $\mathrm{Bb}-46$ & \pm & ++ & ++ & - \\
\hline & A 4.8 & \pm & \pm & ++ & - \\
\hline
\end{tabular}

-: no inhibition; \pm : partial inhibition; +: difficult measured inhibition; ++ : clear, good measured inhibition $(<15$ $\mathrm{mm})$; +++: wide zone of inhibition 


\subsection{Changes in antioxidant capacity of fermentation}

Fruit and vegetable are rich in functional components such as minerals, vitamins, fibre, and antioxidant compounds. The selected fruits and vegetables are rich sources of flavonoid and carotenoid compounds that are bioactive compounds, so they have high antioxidant capacities. These arguments have led us to explore the extent to which antioxidant activity changes during the fermentation. In most cases - though slightly - the antioxidant capacity decreased during fermentation with bifidobacteria (Table 7). Exceptions were orange and carrot juices fermented with B. lactis Bb-12 and B. longum A4.8. The other exception was the tomato juice fermentation, because the antioxidant activities decreased only in case the juice was fermented by $\mathrm{B}$. lactis $\mathrm{Bb}-12$. This result is encouraging, because these compounds are able to maintain their functionality in the fermented juice as well.

Table 7. Changes in antioxidant potential of fermented juices

\begin{tabular}{lcccc}
\hline & \multicolumn{4}{c}{ Antioxidant potential (mg TE (trolox equivalent) $\mathrm{ml}^{-1}$ ) } \\
\cline { 2 - 5 } & Orange juice & Sour cherry juice & $\begin{array}{c}\text { Carrot } \\
\text { juice }\end{array}$ & Tomato juice \\
\hline Initial value & $2.512 \pm 0.070$ & $4.675 \pm 0.133$ & $1.125 \pm 0.980$ & $1.086 \pm 0.308$ \\
A4.8 & $3.517 \pm 0.133$ & $3.536 \pm 0.007$ & $0.838 \pm 1.260$ & $1.279 \pm 0.595$ \\
Bb-12 & $2.705 \pm 0.105$ & $3.036 \pm 0.084$ & $2.863 \pm 1.610$ & $0.828 \pm 0.028$ \\
Bb-46 & $2.601 \pm 0.392$ & $2.729 \pm 0.210$ & $0.591 \pm 0.014$ & $1.234 \pm 0.924$ \\
B3.2 & $2.650 \pm 0.154$ & $3.106 \pm 0.182$ & $0.987 \pm 0.126$ & $1.774 \pm 0.077$ \\
NCFB1454 & $2.566 \pm 0.105$ & $4.135 \pm 0.112$ & $0.571 \pm 0.014$ & $2.417 \pm 0.399$ \\
\hline
\end{tabular}

Values are averages of triplicate results \pm standard deviation

\section{Conclusions}

Our studies were directed towards the application of fruit- and vegetable-based raw material to develop probiotic products. The orange, carrot, and tomato juices served as appropriate medium for cultivating bifidobacteria. The best growth was shown by B. longum Bb-46 in the fruit and vegetable juices. This strain is a dairy starter culture with good techno-functional properties. Against entero- and uropathogenic microorganisms inhibition was observed, which is considered a positive functional property of the applied strains. The antioxidant capacity of juices slightly changed during the fermentation. Based on our results, the development of probiotic fruit and vegetable juices may be prognosticated.

This research is supported by the National Development Agency through Project No. TÁMOP-4.2.1./B-09/1KMR-2010-0005, TÁMOP-4.2.2/B-10/1-2010-0023, and HR-36/2008. 


\section{References}

Alander, M., Mättö, J., Kneifel, W., Johansson, M., Kögler, B., Crittenden, R., Mattila-Sandholm, T. \& SAARELA, M. (2001): Effect of galacto-oligosaccharide supplementation on human faecal microflora and on survival and persistence of Bifidobacterium lactis Bb-12 in the gastrointestinal tract. Int. Dairy J., 11, 817825 .

BeEren's, H. (1990): An elective and selective isolation medium for Bifidobacterium spp. Lett. Appl. Microbiol., 11, $155-157$.

Biavati, B., Vescovo, M., Torriani, S. \& Bottazzi, V. (2000): Bifidobacteria: history, ecology, physiology, and applications. Ann. Microbiol., 50, 117-131.

BLoIs, M.S. (1958): Antioxidant determination by the use of a stable free radical. Nature, 181, 1199-1200.

Brandt, K., Christensen, L.P., Hansen-Møller, J., Hansen, S.L., Haraldsdottir, J., Jespersen, L., Purup, S., Kharazmi, A., Barkholt, V., Frøkier, H. \& Kobek-Larsen, M. (2004): Health promoting compounds in vegetables and fruits: A systematic approach for identifying plant components with impact on human health. Trends Food Sci. Tech., 15(7-8), 384-393.

Eskin, N.A. \& TAmiR, S. (2006): Dictionary of nutraceuticals and functional foods. CRC Press Inc. Taylor \& Francis Group, Boca Raton, FL, USA, p. 507.

Herrmann, K. (2001): Wurzel- und Knollengemüse. -in: Herrmann, K. (Ed.) Inhaltstoffe von Obst und Gemüse. Verlag Eugen Ulmer GmbH \& Co., Stuttgart, pp. 95-98.

KAMALY, K.M. (1997): Bifidobacteria fermentation of soybean milk. Food Res. Int., 30, 675-682.

Kaur, I.P., Chopra, K. \& SAInI, A. (2002): Probiotics: potential pharmaceutical applications. Eur. J. Pharm. Sci., 15, $1-9$.

Lavermicocca, P. (2006): Highlights on new food research. Digest. Liver Dis., 38, 295-299.

Luckow, T. \& Delahunty, C. (2004): Which juice is healthier? A consumer study of probiotic non-dairy juice drinks. Food Qual. Prefer., 15, 751-759.

MAYer, A., SEILER, H. \& Scherer, S. (2003): Isolation of bifidobacteria from food and human faeces and identification by Fourier transform infrared spectroscopy. Ann. Microbiol., 53, 299-313.

Mercenier, A., Pavan, S. \& Pot, B. (2002): Probiotics as biotherapeutic agents: Present knowledge and future prospects. Curr. Pharm. Design, 8, 99-110.

Netzel, M., Strass, G., Kaul, C., Bitsch, I., Dietrich, H. \& Bitsch, R. (2002): In vivo antioxidative capacity of a composite berry juice. Food Res. Int., 35, 213-216.

Pennington, J.A.T. (2002): Food composition databases for bioactive food components. J. Food Compos. Anal., 15, $419-434$.

Saarela, M., Alakomi, H.L., Mättö, J., Ahonen, A. M., Puhakka, A. \& Tynkkynen S. (2011): Improving the storage stability of Bifidobacterium breve in low pH fruit juice. Int. J. Food Microbiol., 149, 106-110.

Scalabrini, P., Rossi, M., Spettoli, P. \& Matteuzzi, D. (1998): Characterization of Bifidobacterium strains for use in soy milk fermentation. Int. J. Food Microbiol., 39, 213-219.

Scardovi, V. (1981): The Genus Bifidobacterium. -in: Starr M.P., Stolp, H., TrüPer, H.G., Balows, A. \& Shlegel, H.G. (Eds) The Prokaryotes Vol 2, Springer-Verlag, New York, pp. 1951-1961.

Slačanac, V., Hardi, J., Pavlovič, H., Vukovič, D. \& Čutič, V. (2004): Inhibitory effect of goat and cow milk fermented by ABT-2 culture (Lactobacillus acidophilus La-5, Bifidobacterium lactis Bb-12 and Streptococcus thermophilus) on the growth of some uropathogenic E. coli strains. Ital. J. Food Sci., 16, 227-237.

TAGG, J.R. \& McGiven, A.R. (1971): Assay system for bacteriocins. Appl. Microbiol. ,21, 943. 